\title{
Patients with hypertrophic cardiomyopathy (HCM) and HCM gene carriers have attenuated myocardial oxygenation response to vasodilator stress - a potential mechanism for sudden cardiac death
}

\author{
Sairia Dass ${ }^{1 *}$, Theodoros Karamitsos ${ }^{1}$, Joseph Suttie ${ }^{1}$, Emily Sever $^{1}$, Michael Jerosch-Herold ${ }^{2}$, Hugh Watkins ${ }^{1}$, \\ Stefan Neubauer ${ }^{1}$
}

From 15th Annual SCMR Scientific Sessions

Orlando, FL, USA. 2-5 February 2012

\section{Summary}

Tissue oxygenation response to adenosine stress in patients with hypertrophic cardiomyopathy (HCM) is blunted compared to athletes and normals. Myocardial tissue hypoxia during stress in HCM may potentially contribute to the increased exercise related deaths in this condition.

\section{Background}

By exploiting the paramagnetic properties of deoxyhemoglobin, blood oxygen level-dependent (BOLD) MRI can detect myocardial ischemia in patients with coronary artery disease. However, little is known about myocardial tissue oxygenation in pathological left ventricular hypertrophy (e.g. HCM) or physiological hypertrophy (e. g. elite athletes). Perfusion studies have shown that patients with HCM show evidence of microvascular dysfunction, however, whether this leads to de-oxygenation and ischemia is unclear.

\section{Methods}

Sixty nine age and gender matched subjects (26 HCM; 11 HCM gene carriers without hypertrophy; 12 athletes; 20 normal controls, )were studied at 3 Tesla (Siemens Tim Trio), with acquisition of BOLD (using aT2-prepared sequence) and first-pass perfusion images (using a saturation recovery fast-gradient echo sequence and 0.03

\footnotetext{
'Deprtment of Cardiovascular Medicine, University of Oxford, Oxford, UK Full list of author information is available at the end of the article
}

$\mathrm{mmol} / \mathrm{kg}$ Gd-DTPA bolus) at stress and rest (4-6 minutes i.v. adenosine, $140 \mu \mathrm{g} / \mathrm{kg} / \mathrm{min})$. Signal intensity change $(\operatorname{SI} \Delta)$ and myocardial perfusion reserve index (MPRI) were measured from BOLD and perfusion images, respectively.

\section{Results}

During stress there were equivalent rises in rate pressure product in all groups, (normal $73 \pm 20 \%$, HCM $74 \pm 50 \%$, athlete $80 \pm 38 \%, \mathrm{P}=\mathrm{NS})$.

There was a significantly reduced BOLD SI $\Delta$ response in both HCM gene carriers and HCM (BOLD SI $\triangle$ : 10 $\pm 11 \%$ gene carriers; $8 \pm 10 \% \mathrm{HCM} \mathrm{P}<0.0001$ vs normal, figure 1) compared to athletes $(17 \pm 10 \%)$ and normal volunteers $(18 \pm 14 \% \mathrm{P}=0.8)$. MPRI was also significantly reduced in HCM, (normal controls: $1.8 \pm 0.6$; athletes: 2.0 $\pm 0.9, \mathrm{P}=0.005$; HCM gene carriers: $1.6 \pm 0.7 \mathrm{P}=0.001$; HCM: $1.3 \pm 0.6 \mathrm{P}<0.0001$, figure 2$)$. There was a weak but significant correlation between BOLD SI $\Delta$ and MPRI per segment, $(\mathrm{R}=0.27, \mathrm{P}<0.0001)$ and between BOLD SI $\Delta$ and end diastolic wall thickness per segment, $(\mathrm{R}=0.24, \mathrm{P}<0.001)$. Linear regression analysis showed that both MPRI $(\beta$ 0.2, $\mathrm{P}<0.001)$ and wall thickness $(\beta$ $0.2, \mathrm{P}<0.001)$ are independent predictors of BOLD SI $\Delta$.

\section{Conclusions}

Patients with HCM as well as HCM gene carriers without evidence of hypertrophy show blunted myocardial oxygenation response to vasodilator stress compared to 


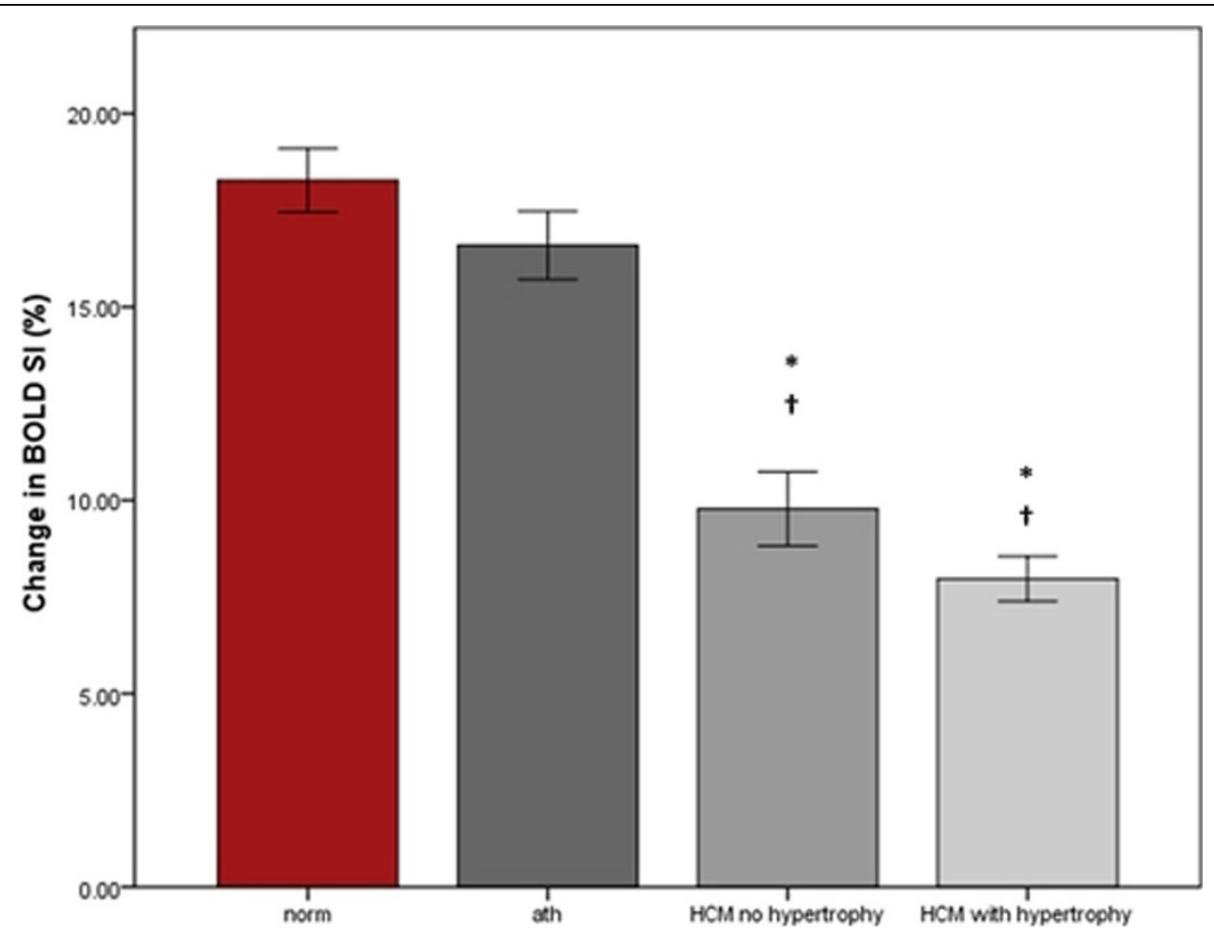

Figure 1 The mean and standard deviation of BOLD SI $\triangle \%$ with adenosine stress in normal, athletes, and HCM patients with and without hypertrophy. Error pars: standard error. ${ }^{*} \mathrm{P}<0.001$ compared to normal; $+\mathrm{P}<0.001$ compared to athletes.



Figure 2 The mean and standard deviation of MPRI with adenosine stress in normal, athlete, HCM with and without hypertrophy. Error pars: standard error. ${ }^{*} \mathrm{P}<0.001$ compared to normal; $+\mathrm{P}<0.001$ compared to athletes; $\gamma \mathrm{P}<0.05$ compared to HCM with no hypertrophy. 
normal controls and athletes. The increased energy cost, and thus oxygen demand, of contraction in HCM, regardless of the degree of phenotype expression, together with barriers to oxygen supply due to the impaired perfusion are the most likely pathophysiological mechanisms of de-oxygenation in these patients. Importantly, myocardial tissue hypoxia may play a significant pathophysiological role being potentially responsible for stress-induced arrhythmia and sudden death in HCM.

\section{Funding}

This research is funded by the British heart foundation.

\section{Author details}

'Deprtment of Cardiovascular Medicine, University of Oxford, Oxford, UK.

${ }^{2}$ Radiology, Brigham and Women's Hospital, Boston, MA, USA.

Published: 1 February 2012

doi:10.1186/1532-429X-14-S1-P157

Cite this article as: Dass et al:: Patients with hypertrophic

cardiomyopathy (HCM) and HCM gene carriers have attenuated

myocardial oxygenation response to vasodilator stress - a potential

mechanism for sudden cardiac death. Journal of Cardiovascular Magnetic

Resonance 2012 14(Suppl 1):P157.

Submit your next manuscript to BioMed Central and take full advantage of:

- Convenient online submission

- Thorough peer review

- No space constraints or color figure charges

- Immediate publication on acceptance

- Inclusion in PubMed, CAS, Scopus and Google Scholar

- Research which is freely available for redistribution 